\title{
AMACR and HMWCK as diagnostic tool for confirming prostate adenocarcinoma in needle prostate biopsy
}

\author{
Goswami P.R. ${ }^{1}$, Goswami A.P. ${ }^{2}$ \\ ${ }^{1}$ Dr. Parth Rajendragiri Goswami, Assistant Professor, ${ }^{2}$ Dr. Alpeshpuri P. Goswami, Associate Professor; both authors are \\ attached with Department of Pathology, Government Medical College \& Sir. T. Hospital, Bhavnagar, Gujarat, India.
}

Corresponding Author: Dr. Alpeshpuri P. Goswami, Associate Professor, Department of Pathology, Government Medical College \& Sir. T. Hospital, Bhavnagar, Gujarat, India. Email: goswamiparth42@gmail.com

\begin{abstract}
Introduction: The histopathological examination is always necessary to diagnose prostate adenocarcinoma but it would be better if the diagnosis can be supported with more accuracy by Immunohistochemistry. This study has been carried out to check usefulness of AMACR and HMCK as diagnostic tool to support diagnosis of prostate adenocarcinoma. AMACR stands for alpha-methylacyl-CoA racemase and HMWCK stand for High molecular weight cytokeratin. Material and Methods: The study was done in 50 morphological diagnosed prostate adenocarcinoma cases at tertiary care hospital. AMACR and HMWCK immunohistochemistry was done in all these cases. All the data has been plotted in tabulated form and p value calculated for both AMACR and HMWCK using Fischer's exact and chi-square test. Results: AMACR shows strong cytoplasmic immunoreactivity in almost all prostate cancer cells while HMWCK shows strong nuclear immunoreactivity in almost all benign prostatic epithelial cells. The $\mathrm{p}$ value in both the cases were $<0.0001$ suggesting strong association of AMACR and HMWCK with prostate cancer cases. Conclusion: AMACR and HMWCK both can be used to confirm morphologically diagnosed prostate adenocarcinoma cases and it should be used in all cases of prostate carcinoma to confirm the diagnosis by immunohistochemistry.
\end{abstract}

Keywords: Prostate adenocarcinoma, AMACR, HMWCK, Immunohistochemistry

\section{Introduction}

PSA that is prostate specific antigen is used commonly nowadays for screening prostate cancer [1]. However, PSA lack the specificity and it can be raised in inflammation, benign prostatic hyperplasia as well. So there is need for taking prostate biopsy whenever clinical suspicion of prostate cancer is present $[2,3]$.

The histopathological examination is always necessary to diagnose prostate adenocarcinoma but it would be better if the diagnosis can be supported with more accuracy by Immunohistochemistry. This study has been carried out to check usefulness of AMACR and HMCK as diagnostic tool to support diagnosis of prostate adenocarcinoma. The AMACR stands for alpha-methylacyl-CoA racemase and HMWCK stand for High molecular weight cytokeratin. The prostate adenocarcinoma diagnosed histopathologically by stromal invasion, back to back small uniform gland, nuclear atypia and absence of basal cell layer. In few studies it has been observed that AMACR is over expressed in prostate cancer cells as compare to normal prostate epithelium and

Manuscript received: $30^{\text {th }}$ October 2019

Reviewed: $10^{\text {th }}$ November 2019

Author Corrected: $17^{\text {th }}$ November 2019

Accepted for Publication: $22^{\text {nd }}$ November 2019 benign glands. So AMACR antibody immunohistochemistry can be used as one of the diagnostic tools for prostate cancer $[4,5,6,7]$. It is well known that basal cell layer is absent in prostate cancer, hence the basal cell layer marker also can be used for immunohistochemistry to confirm their absence. HMWCK is one of such markers used to stain basal cells layer and so negative staining for HMWCK in cancer cells further support cancer diagnosis $[8,9,10]$. In the present study aims to discuss regarding utility of both these immunohistochemical marker.

\section{Material and Methods}

Setting Design of study: Prostatic biopsies histopathology analysis \& AMACR and HMWCK antibody immunohistochemistry analysis were done.

Immunohistochemistry is a procedure to stain specific selective antigen in tissue with using appropriate antibody. Here in this case AMACR and HMWCK antigen stained using applying antibody against them.

The biopsy means removal of some portion of tissue for histopathology analysis.

Pathology Update: Tropical Journal of Pathology \& Microbiology Available online at: www.medresearch.in 920 | P a g e 
Duration \& type of study: The study was done on received prostatic biopsies from the duration of year 2014-2018 at histopathology laboratory of tertiary care hospital. It is prospective study.

Sample size: The present have included 50 prostatic biopsies for this study which were given the diagnosis of prostate adenocarcinoma.

Sample methods: All biopsies were processed in automatic tissue processor and thin sections were cut in microtome from prepared wax block. One section prepared for routine histopathology staining $(\mathrm{H} \& \mathrm{E})$ and other two sections were stained by immunohistochemistry processing for AMACR and HMWCK antibody.

Inclusion criteria: In the current study, 50 prostatic biopsy were included whose routine histopathological microscopic diagnosis was done as prostate adenocarcinoma.
Exclusion criteria: The current study have excluded benign prostatic hyperplasia from the study because the current study aimed to analyze use of AMACR and HMWCK in adenocarcinoma only.

Method: Both the histopathological study and Immunohistochemistry study were done in microscope by two different pathologists to avoid bias. AMACR and HMWCK positivity were studied in prostate cancer cells and normal prostate epithelium in all 50 morphologically diagnosed cases.

Statistic: All the data has been plotted in tabulated form and $\mathrm{p}$ value calculated for both AMACR and HMWCK using Fischer's exact and chi-square test.

\section{Results}

The mean age group of all positive prostate cancer patients was 58 year. PSA were elevated above $10 \mathrm{ng} / \mathrm{l}$ in 46 cases of prostate cancer.

It has been observed in the present study that AMACR were almost strong positive in all prostate cancer epithelial cells and HMWCK were weak positive or negative in prostate cancer epithelial cells but were strong positive in normal prostate epithelial cells and glands.

Table-1: Statistical association of AMACR positivity in prostate adenocarcinoma cases.

\begin{tabular}{|c|c|c|c|}
\hline & $\begin{array}{c}\text { \% of prostate cancer } \\
\text { epithelial cell positivity }\end{array}$ & $\begin{array}{c}\text { \% of normal benign prostate } \\
\text { epithelial cells positivity }\end{array}$ & P value \\
\hline $\begin{array}{c}\text { AMACR cytoplasmic strong } \\
\text { immunoreactivity }\end{array}$ & 48 & 02 & P value \\
\hline $\begin{array}{c}\text { AMACR negativity or weak } \\
\text { immunoreactivity }\end{array}$ & 02 & 48 & $<0.0001$ \\
\hline
\end{tabular}

Table-2: Statistical association of HMWCK positivity in prostate adenocarcinoma cases.

\begin{tabular}{|c|c|c|c|}
\hline & $\begin{array}{c}\text { \% of prostate cancer } \\
\text { epithelial cell positivity }\end{array}$ & $\begin{array}{c}\text { \% of normal benign prostate } \\
\text { epithelial cells positivity }\end{array}$ & P value \\
\hline $\begin{array}{c}\text { HMWCK nuclear strong } \\
\text { immunoreactivity }\end{array}$ & 03 & 47 & $\begin{array}{c}\text { P value } \\
<0.0001\end{array}$ \\
\hline $\begin{array}{c}\text { HMWCK nuclear negative } \\
\text { immunoreactivity }\end{array}$ & 47 & 03 & \\
\hline
\end{tabular}

The strong positivity in AMACR include circumferential, granular, luminal to diffuse cytoplasmic positivity which should be visible in 20x objective lense as well.

The weak or negative staining include non circumferential weak or absent staining. AMACR shows cytoplasmic positivity while HMWCK shows nuclear stain positivity (Figure 1-4). 


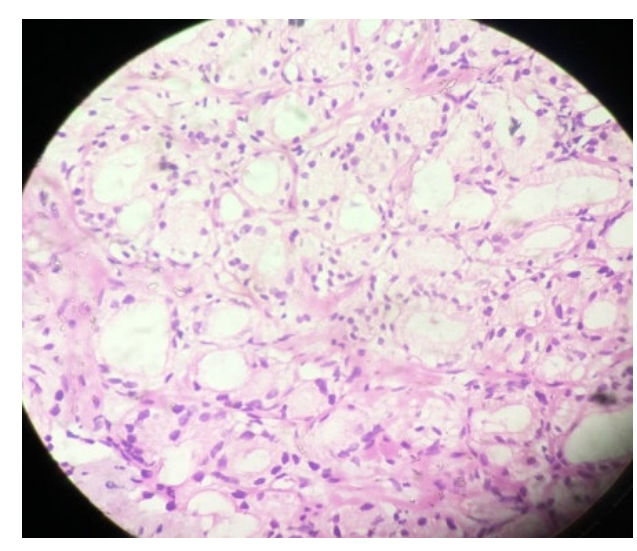

Fig-1: Histopathological microscopic prostate adenocarcinoma.

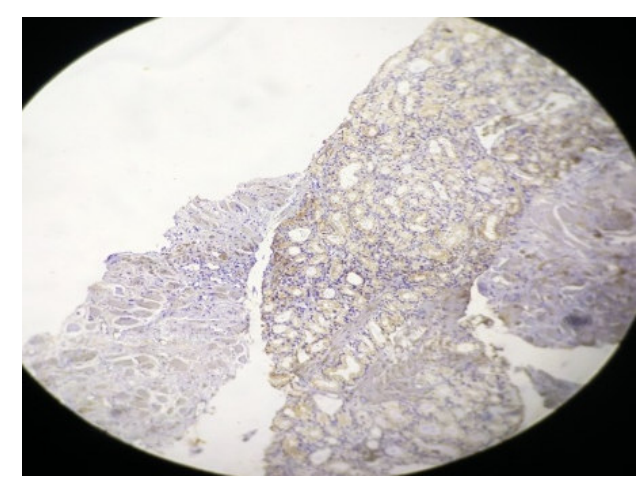

Fig-2: AMACR strong immunoreactivity in prostate cancer cells low power lense.

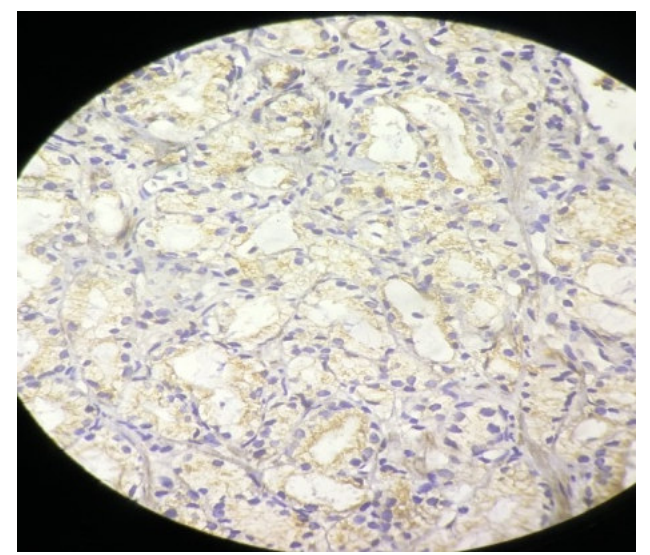

Fig-3: AMACR strong immunoreactivity in prostate cancer cells high power lense.

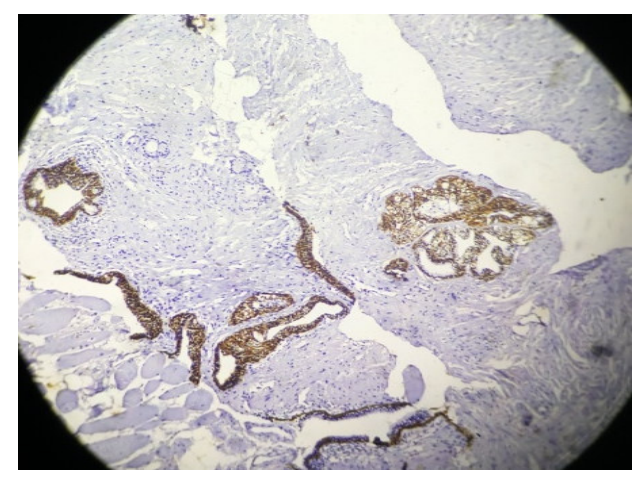

Fig-4: HMWCK immunoreactivity in normal prostatic gland or cells. 
The $\mathrm{p}$ value in both the cases were $<0.0001$ suggesting strong association of AMACR and HMWCK with prostate cancer cases and so can be used as adjunctive diagnostic tool in prostate cancer diagnosis (Table $1 \& 2$ ).

\section{Discussion}

There are few studies done for AMACR immunohistostaining in prostate cancer cases and prostatic hyperplasia cases. They showed strong positivity for AMACR immunoreactivity prostate adenocarcinoma cases. The staining should be circumferential strong positive in 20x objective lenses as well $[6,11,12,13,14]$. Zhou $\mathrm{M}$ et al. Study concluded that AMACR has been demonstrated to be over-expressed in localized and metastatic prostate cancer, suggesting that it may be an important tumor marker [11].

Beach Ret al. concluded in his study that P504S(AMACR) is best used only in conjunction with strict light microscopic correlation and preferably with high molecular weight cytokeratin immunostaining [12].

Yang et al. concluded in study that the biologic significance of P504S expression in a small subset of AAH remains to be determined. Because most cases of AAH are negative for P504S, immunostaining of P504S is also of diagnostic value in distinguishing the majority of AAHs from prostatic adenocarcinoma. So, in prostate adenocarcinoma AMACR is over expressed [13].

Kuefer R et al. Done study Analysis by standard slides and high-density tissue microarrays. AMACR protein expression was significantly increased in localized hormone-naive $\mathrm{PCa}$ as compared to benign $(\mathrm{P}<0.001)$ [14]. In the present study as well, almost all prostate cancer cells showed strong positivity for AMACR which correlate with all above mentioned studies as well. In our case also $p$ value was <.0001 suggesting strong association of AMACR positivity in Prostate adenocarcinoma.

Signoretti et al. results indicate that p63 is required for prostate development and support the hypothesis that basal cells represent and/or include prostate stem cells. Furthermore, their results show that p63 immunohistochemistry may be a valuable tool in the differential diagnosis of benign versus malignant prostatic lesions [8].

Parsons JK concluded that in contrast to normal and preneoplastic prostatic tissue, the vast majority of prostate adenocarcinomas do not express p63. Therefore, p63 immunohistochemistry represents a potential novel adjuvant method for facilitating the pathologic diagnosis of prostate cancer in prostate needle biopsies [9]. Weinstein MH et al concluded that p63 staining is at least as sensitive and specific for the identification of basal cells in diagnostic prostate specimens as is high molecular weight cytokeratin staining [10].
In the present study as well HMWCK or p63 were negative in prostate cancer cells and positive in normal prostate gland and epithelium. The $p$ value was $<0.00001$ suggesting strong correlation with negative in cancer cells and positive in Benign cells of prostate. Few studies were done using AMACR tissue microarray that suggesting AMACR mRNA over expression in prostate cancer cells compare with BPH [15].

So, in the present study, findings for positive AMACR in cancer cells and negative HMWCK in prostate cancer cells also correlated with other studies as well as mentioned above. AMACR and HMWCK can be used as cocktail for confirming Prostate cancer diagnosis. However Prostate cancer cannot diagnose based on only these two IHC stain. It can support the diagnosis but cannot replace morphological microscopic routine H\&E staining analysis of biopsy for prostate cancer diagnosis. So, Immunohistochemistry study and morphological microscopic analysis both together can be more accurate in giving prostate adenocarcinoma diagnosis.

\section{Conclusion}

It can be concluded from the present study that AMACR was consistently over expressed in malignant prostate cancer cells and HMWCK was consistently positive in normal benign prostate glands or epithelial cells. Hence it is recommended the use of these two IHC markers to support diagnosis of prostate carcinoma especially in case of smaller biopsy where diagnostic dilemma arise due to presence of both benign and malignant cells in routine microscopic examination of biopsy.

\section{What the study adds to the existing knowledge?}

Immunohistochemistry study and morphological microscopic analysis both together can be more accurate in giving prostate adenocarcinoma diagnosis. In diagnostic dilemma case of prostate adenocarcinoma, the AMACR and HMWCK both can be beneficial to confirm the diagnosis.

\section{Author's contribution}

Dr. Parth Rajendragiri Goswami: Conception and design, Analysis and interpretation of the data, Drafting of the article, Provision of study materials or patients, Statistical expertise, Collection and assembly of data.

Dr. Alpeshpuri P. Goswami: Conception and design, Analysis and interpretation of the data, Critical revision of

Pathology Update: Tropical Journal of Pathology \& Microbiology Available online at: www.medresearch.in 923 | P a g e 
the article for important intellectual content, Final approval of the article, Provision of study materials or patients, Administrative, technical, or logistic support, Collection and assembly of data.

Funding: No funding sources

Conflict of interest: None declared

Ethical Approval: This study was approved by the Institutional Ethics Committee

\section{Reference}

1. Lu-Yao G, Stukel TA, Yao SL. Prostate-specific antigen screening in elderly men. J Natl Cancer Inst. 2003; 95(23): 1792-1797. doi: https://doi.org/10.1093/jnci/djg104.

2. Etzioni R, Penson DF, Legler JM, di Tommaso D, Boer $\mathrm{R}$, Gann PH, et al. Overdiagnosis due to prostate-specific antigen screening: lessons from U.S. prostate cancer incidence trends. J Natl Cancer Inst. 2002; 94(13):981-990. doi: https://doi.org/10.1093/jnci/94.13.981.

3. Draisma G, Boer R, Otto SJ, van der Cruijsen IW, Damhuis RA, Schroder FH, et al. Lead times and over detection due to prostate-specific antigen screening: estimates from the European Randomized Study of Screening for Prostate Cancer. J Natl Cancer Inst. 2003;95 (12):868-878. doi: https: //doi.org/ 10.1093/jnci/ 95.12. 868 .

4. Xu J, Stolk JA, Zhang X, Silva SJ, Houghton RL, Matsumura $M$, et al. Identification of differentially expressed genes in human prostate cancer using subtraction and microarray. Cancer Res. 2000;60(6):1677-1682.

5. Luo J, Duggan DJ, Chen Y, Sauvageot J, Ewing CM, Bittner ML, et al. Human prostate cancer and benign prostatic hyperplasia: molecular dissection by gene expression profiling. Cancer Res., 2001; 61(12): 46834688.

6. Rubin MA, Zhou M, Dhanasekaran SM, Varambally S, Barrette TR, Sanda MG, et al. Alpha-methylacyl coenzyme Aracemase as a tissue biomarker for prostate cancer. JAMA. 2002; 287(13):1662-1670. doi:10.1001/jama.287. 13. 1662
7. Jiang Z, Woda BA, Rock KL, Xu Y, Savas L, Khan A, et al. P504S: a new molecular marker for the detection of prostate carcinoma. Am J Surg Pathol. 2001; 25(11):13971404

8. Signoretti S, Waltregny D, Dilks J, Isaac B, Lin D, Garraway L, Yang A, Montironi R, McKeon F, Loda M. p63 is a prostate basal cell marker and is required for prostate development. Am J Pathol. 2000;157(6):17691775. doi: https://doi.org/10.1016/S0002-9440(10)64814-6

9.Parsons,J. K., Gage, W. R., Nelson, W. G., and De Marzo, A.M. Expression of p63in normal, neoplastic and preneoplastic human prostate tissues. Urol. 2001;58 (4):619-624. doi: https://doi.org/10.1016/S0090-4295(01)01311-5.

10. Weinstein MH, Signoretti S, Loda M. Diagnostic utility of immunohistochemical staining for p63, a sensitive marker of prostatic basal cells. Mod Pathol. 2002;15(12): 1302-1308. doi:10.1097/01.MP.0000038460.95912.6E.

11. Zhou M, Chinnaiyan AM, Kleer CG, Lucas PC, Rubin MA. Alpha-methylacyl-CoA racemase: a novel tumor marker over-expressed in several human cancers and their precursor lesions. Am J Surg Pathol. 2002;26(7):926-931.

12. Beach R, Gown AM, De Peralta-Venturina MN, Folpe AL, Yaziji H, Salles PG, et al. P504Simmunohistochemical detection in 405 prostatic specimens including 376 18gauge needle biopsies. Am J Surg Pathol. 2002;26(12): 1588-1596.

13. Yang XJ, Wu CL, Woda BA, Dresser K, Tretiakova M, Fanger GR, et al. Expression of alpha-methylacyl-Co Aracemase (P504S) in atypical adenomatous hyperplasia of the prostate. Am J Surg Pathol. 2002;26(7): 921-925.

14. Kuefer R, Varambally S, Zhou M, Lucas PC, Loeffler $\mathrm{M}$, Wolter $\mathrm{H}$, et al. Alpha-methylacyl-CoA racemase: expression levels of this novel cancer biomarker depend on tumor differentiation. Am J Pathol. 2002;161(3):841-848. doi: 10.1016/s0002-9440(10)64244-7.

15. Epstein JI, Potter SR. The pathological interpretation and significance of prostate needle biopsy findings: implications and current controversies. J. Urol. 2001; 166 (2) : 402-410.

\section{How to cite this article?}

Goswami P.R, Goswami A.P. AMACR and HMWCK as diagnostic tool for confirming prostate adenocarcinoma in needle prostate biopsy. Trop J Path Micro 2019;5(11):920-924. doi: 10.17511/jopm.2019.111.14 